\title{
Peningkatan Kapasitas Kader dalam Screening Kesehatan Remaja Di Program Pashmina
}

\author{
Aswad Ishak ${ }^{1^{*}}$, Sri Sumaryani ${ }^{2}$ \\ 1. Program Studi Ilmu Komunikasi, Fakultas ilmu Sosial dan ilmu Politik, Universitas Muhammadiyah Yogyakarta, Jalan Brawijaya, \\ Tamantirto, Kasihan, Bantul, 55183 (0274) 387656 \\ 2 Program Studi Ilmu Keperawatan, Fakultas Kedokteran dan Ilmu Kesehatan, Universitas Muhammadiyah Yogyakarta, Jalan \\ Brawijaya, Tamantirto, Kasihan, Bantul, 55183 (0274) 387656 \\ Email: ishak@umy.ac.id; srisumaryani@umy.ac.id \\ DOI: $10.18196 / p p m .39 .117$
}

\begin{abstract}
Abstrak
Masa remaja ditandai dengan perubahan, baik fisik maupun psikis. Remaja aktif melakukan pencarian informasi dari berbagai sumber, media massa maupun online. Teman sebaya sebagai partner dalam berdiskusi tentang kesehatan reproduksi. Meskipun ada rasa ingin tahu yang tinggi dan kemudahan akses informasi melalui teknologi komunikasi, informasi kesehatan reproduksi yang diterima oleh remaja secara bebas tidak semuanya benar. Pada saat remaja bertanya dengan teman sebaya kurang lebih pemahamannya sama, sedangkan remaja sangat membutuhkan informasi yang benar. Oleh karena itu, diperlukan pendampingan yang tepat oleh lembaga yang memiliki concern sama. Lembaga yang memiliki fokus pada persoalan remaja adalah Nasyiatul Aisyiyah Cabang Bantul dengan program Pashmina (Pelayanan Remaja Sehat Nasyiatul Aisyiyah yang menangani permasalahan kesehatan reproduksi remaja. Program ini melibatkan kader sebagai pendamping remaja yang mengonsultasikan permasalahannya. Para pendamping perlu mendapat bekal pengetahuan dan keterampilan dalam melakukan penanganan permasalahan yang dihadapi. Program pembekalan dalam rangka peningkatan pengetahuan dan keterampilan para pendamping Pashmina diawali dari penggalian data kepada stakeholder, yaitu kelompok remaja, orang tua, guru, pendamping program untuk memahami kebutuhan yang ada. Program yang dilaksanakan adalah pelatihan komunikasi dalam pendampingan dan pembekalan pengetahuan terkait kesehatan reproduksi yang baik dan benar.
\end{abstract}

Kata Kunci: komunikasi, kesehatan reproduksi, kader, Pashmina, remaja

\section{Pendahuluan}

Masa remaja merupakan masa yang rentan dengan permasalahan, baik masalah pribadi maupun sosial. Permasalahan remaja menjadi tanggung jawab keluarga, sekolah, dan lingkungan sosial. Salah satu unit penanganan masalah siswa di sekolah adalah unit pelayanan bimbingan konseling yang memiliki peran dan fungsi yang strategis dalam pola pembentukan karakter dan perilaku. Meskipun demikian, masih sedikit siswa/remaja memanfaatkan bimbingan dan konseling di sekolah untuk membantu menyelesaikan masalahnya atau mengembangkan potensi dirinya. Bimbingan dan konseling masih sering dianggap oleh siswa/remaja sebagai lembaga pengadil bagi perilaku negatif yang dilakukan. Salmiyati (2018) menyebutkan bahwa konseling dengan teman sebaya, remaja menjadi lebih terbuka dan dapat bercerita banyak.

Status kesehatan remaja dipengaruhi oleh perkembangan teknologi informasi. Kemudahan akses informasi dan teknologi dapat berdampak buruk bagi remaja apabila remaja tidak memiliki bekal pengetahuan yang baik dan memadai. Perkembangan informasi dan teknologi dapat memengaruhi perilaku remaja termasuk perilaku merokok dan penggunaan obat-obat terlarang, bahkan perilaku seksual berisiko. Berdasarkan data survei dari BKKBN dan BPS (2018) menyebutkan mayoritas wanita dan pria yang mengetahui tentang kesehatan reproduksi mendiskusikannya dengan teman, masing-masing $62 \%$ dan $51 \%$. Lima puluh tiga persen wanita berdiskusi dengan ibu dan $42 \%$ pria berdiskusi dengan guru. Persentase yang mendiskusikan kesehatan reproduksi dengan ayah, $4 \%$ pada wanita dan $8 \%$ pada pria. Ketidaktahuan remaja tentang kesehatan reproduksi membuat remaja sering berdiskusi dengan teman-temannya, sedangkan teman-teman dari remaja ini adalah teman yang secara pengetahuan tidak memiliki kemampuan yang kompeten untuk memberikan konseling karena tidak memiliki 
pengetahuan terkait dengan kesehatan reproduksi. Alhasil, para remaja hanya mendiskusikannya dan mencari dari sumber-sumber yang tidak dapat dipercaya kebenarannya. Hal ini mendorong remaja sering terjebak pada kasus-kasus penyimpangan seksual yang sering terjadi pada remaja (BKKBN, 2018).

Nasyiatul Aisyiyah memiliki program Pelayanan Remaja Sehat Nasyiatul Aisyiyah (Pashmina). Pashmina menjadi program di daerah, cabang, dan ranting, tak terkecuali di Bantul. Pashmina PDNA Bantul memiliki volunteer yang terdiri atas 31 orang dengan berbagai latar belakang pendidikan, 20\% dari volunteer berlatar belakang kesehatan dan sisanya berlatar belakang pendidikan, ilmu sosial, dan ilmu agama. Pelayanan Pashmina sering terkendala karena volunteer yang berlatar belakang kesehatan sering tidak dapat hadir sesuai jadwal pelayanan yang ditetapkan karena pekerjaan atau menjalankan tugas akademik. Volunteer yang sering hadir dalam setiap pelayanan Pashmina adalah yang berlatar belakang selain kesehatan. Kondisi ini membuat pelayanan Pashmina terkendala sehingga ada beberapa pos konseling yang sering tidak terisi.

Pashmina Bantul sudah memiliki beberapa anak cabang yang berdiri di masing-masing cabang dan ranting yang ada di Bantul. Akan tetapi, belum semua Pimpinan Cabang Nasyiatul Aisyiyah di Bantul yang memiliki Pashmina aktif melaksanakan pelayanan Pashmina. Pimpinan Cabang Nasyiatul Aisyiyah yang sudah memiliki Pashmina dan aktif menjalankan pelayanan Pashmina terkendala kurangnya volunteer di bidang pendidikan kesehatan. Dalam layanan Pashmina dari cabang sering memanggil volunteer dari Pimpinan Daerah Nasyiatul Aisyiyah untuk mengisi pos konsultasi reproduksi dan gizi. Ketiadaan pos konsultasi gizi dan reprodukasi membuat pelayanan Pashmina terhambat. Terkadang, ketika tidak ada yang mengisi kedua pos tersebut, Pashmina tetap berjalan, tetapi yang berjalan hanya pos penimbangan berat badan, pengukuran tinggi, badan pengukuran imt, dan pengecekan tekanan darah.

Berbagai macam cara telah dilakukan oleh Pimpinan Daerah Nasyiatul Aisyiyah Bantul. Salah satunya dengan melaksanakan pelatihan volunteer ke beberapa cabang yang ada di Bantul. Pelatihan ini diisi oleh beberapa pakar dari masing-masing bidang. Pada pos gizi diisi oleh ahli gizi, pada pos konsultasi reproduksi diisi oleh bidan, pada pos konsultasi psikologi diisi oleh psikolog. Hasil dari pelatihan yang telah dilaksanakan sejauh ini dirasa masih kurang efektif karena kurang lamanya pelatihan, cara berkonsultasi agar menggali semua permasalahan peserta, dan kurangnya modul konsultasi untuk dibawa pulang dalam latihan. Kebanyakan volunteer yang berasal dari kalangan awam atau nonmedis terkendala dalam cara memberikan konsultasi kepada peserta Pashmina terutama pada pos konsultasi gizi dan reproduksi. Teknik komunikasi kepada peserta Pashmina juga menjadi salah satu kendala dari konsultasi Pashmina ini. Kendala yang dilami, antara lain dalam memberikan pertanyaan karena selama konsultasi saat pelatihan konsultasi yang diajarkan adalah cara menjawab pertanyaan saja dengan bahasa medis dan tidak diajarkan cara berkomunikasi. Para volunteer yang berlatar belakang pendidikan awam sangat kesulitan dalam membuat jawaban atau memberikan konseling pada peserta Pashmina (Surahman). Oleh karena itu, pelatihan peningkatan kapasitas kader dalam melakukan komunikasi menjadi penting untuk melakukan. Komunikasi yang tepat akan mencapai tujuan yang diharapkan.

\section{Metode Pelaksanaan}

Kegiatan pelatihan ini dilaksanakan melalui beberapa tahap. Tahap pertama, dilaksanakan penggalian informasi. Tahapan ini dilaksanakan dengan menggali informasi dari para remaja usia SMP, orang tua siswa SMP, dan guru SMP, serta melakukan wawancara kepada volunteer Pashmina. Ketiga kategori informan ini diperlukan untuk mendapatkan gambaran mengenai tentang pemahaman mereka terhadap kesehatan reproduksi dan media habit yang dipergunakan untuk mengakses informasi kesehatan reproduksi. Masing-masing kategori 
dilakukan pendalaman data melalui kegiatan focus group discussion (FGD) secara terpisah. Tahap kedua, data yang diperoleh kemudian dipilah dan dilakukan analisis terkait pemahaman informan tentang persoalan kesehatan reproduksi bagi remaja dari perpektif siswa/remaja, orang tua, dan guru. Data mengenai teknik komunikasi konseling yang dilakukan diperoleh dari relawan Pashmina. Tahap ketiga, dilaksanakan pembekalan teknik komunikasi efektif dalam melaksanakan konseling untuk para volunteer Pashmina. Kemampuan komunikasi yang baik akan sangat membantu dalam menjalankan konseling secara tepat kepada para remaja.

\section{Hasil dan Pembahasan}

Program peningkatan kapasitas kader Pashmina dilakukan dengan memperhatikan kebutuhan berdasar dari situasi dan kondisi di lapangan. Pada fase ini need assessment dijalankan. Melalui tahapan ini, dapat diperoleh pemetaan yang jelas mengenai sumber persoalan yang dihadapi oleh mitra. Dalam hal ini, Andri Wahyu Rianingsih, Pengurus Nasyiyatul Aisyiyah Daerah Bantul, menjelaskan bahwa ada kesulitan dalam melaksanakan kegiatan konseling yang dilakukan oleh kader dan volunteer. Hal ini dikarenakan para pegiat layanan konseling untuk remaja berasal dari berbagai latar belakang pendidikan dan hanya sedikit yang berbasis dari pendidikan kesehatan. Kesulitan yang ditemui adalah ketidaktahuan secara mendalam mengenai isi/materi konseling. Apabila volunteer sebagai komunikator tidak memahami isi/materi bahasan yang akan dikonselingkan, pesan yang akan ditransmisikan juga tidak dapat ditangkap secara jelas oleh remaja sebagai komunikan. Secara sederhana, konsep komunikator, pesan, media, komunikan menjadi dasar bagi tercapainya komunikasi yang baik.

Fikiri Manalani, sebagai salah satu volunteer Pashmina, menyebutkan bahwa selama melaksanakan kegiatan konseling para relawan yang bertugas ini mengalami kesulitan dalam menggali informasi yang dimiliki oleh remaja yang memiliki persoalan dan datang ke layanan Pashmina untuk mendapatkan solusi terbaik. Hal ini menandakan bahwa kurangnya kemampuan berkomunikasi yang baik dan tepat dengan audiens akan memicu kemandekan proses komunikasi yang berlangsung. Dalam tataran yang lebih jauh lagi, dapat memicu ketidakpercayaan remaja sebagai klien terhadap layanan yang diselenggarakan dan secara personal akan mengarah pada kredibilitas komunikator yang rendah. Hal ini akan berpotensi menjadi ketidakpercayaan klien terhadap konselornya. Menurut Hanif dan Maulina (2015) mengutip Flay dan Burton (2007) (dalam Ishak, 2015) menjelaskan bahwa ada tujuh kondisi yang diperlukan untuk mencapai kesuksesan kampanye komunikasi yang efektif, yakni meningkatkan kualitas pesan, sumber, dan media; menyebarluaskan stimulus kepada target audiens; perhatian yang menarik komunikasi, menorong komunikasi interpersonal; mengubah kesadaran, pengetahuan dan perilaku; penyebab perubahan melalui komunitas dan regulasi pemerintah; evaluasi untuk mengukur kondisi yang dicapai. 


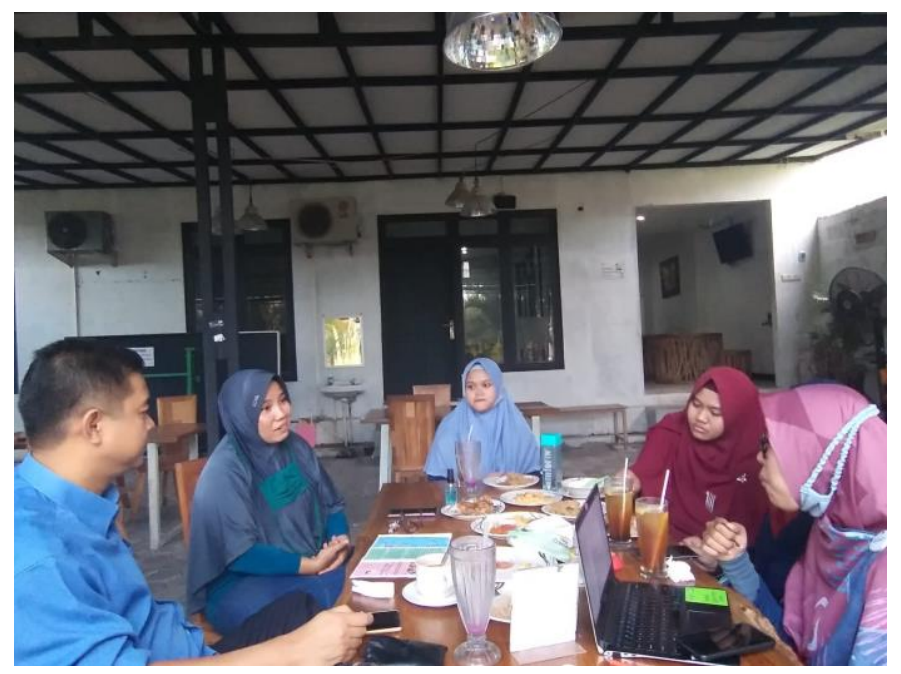

Gambar 1. Pemetaan Masalah dan Potensi dengan Volunteer

Selain itu, siswa/remaja sebagai target audiens utama dalam program layanan Pashmina memberikan gambaran bahwa mereka sudah sangat terbiasa dengan penggunaan gawai untuk berselancar dan mencari informasi di dunia maya. Apabila mengalami persoalan terkait perubahan dalam dirinya sebagai konsekuensi dari peralihan fase anak ke remaja, mereka lebih terbiasa untuk melakukan obrolan dengan teman terdekat. Hal in menandakan peran dan posisi teman sebaya menjadi sangat penting dalam komunikasi kesehatan reproduksi. Namun, temuan lain yang menarik adalah remaja tersebut lebih suka kalau mendapat penjelasan dari para guru. Ini merupakan hal positif terkait relasi murid dengan guru. Hal ini menunjukkan bahwa guru masih dipercaya dan sangat diharapkan oleh remaja untuk memberikan informasi yang benar terkait kesehatan reproduksi.

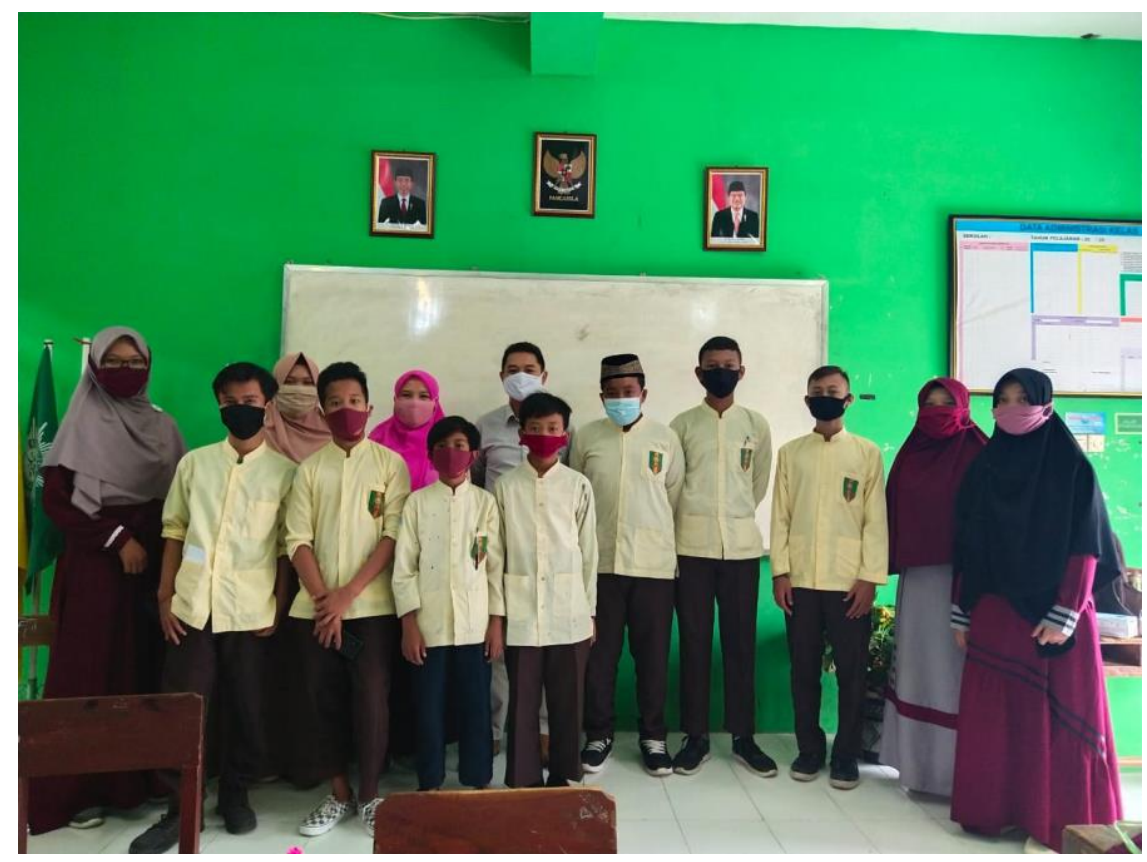

Gambar 2. Pemetaan Masalah dan Potensi dengan Volunteer

Temuan menarik lain dari remaja ini adalah dalam mencari informasi mereka cenderung lebih mudah memahami apabila ada tampilan visual/gambar. Harapan siswa/remaja tersebut adalah para guru bisa memberikan penjelasan informasi disertai dengan tampilan visual yang 
menarik. Jadi, dalam hal ini kredibilitas guru masih tinggi untuk menyampaikan informasi yang benar tentang kesehatan reproduksi.

Apabila ditinjau dari sisi guru, diperoleh informasi bahwa siswa/remaja sudah mengalami perubahan pada era serba digital dan terhubung dengan dunia maya dalam waktu yang lama. Guru sebagai wakil orang tua di sekolah memberikan penjelasan mengenai kesehatan reproduksi sebagai materi di dalam mata pelajaran yang relevan seperti pendidikan jasmani dan olahraga, agama, bimbingan konseling. Guru memberikan materi kesehatan reproduksi masih sebatas pada hal yang bersifat umum. Namun, keingintahuan siswa sebagai remaja sangat tinggi, bahkan seringkali sudah melebihi pengetahuan yang diajarkan di kelas dalam proses belajar mengajar. Guru di sekolah tidak bisa memberikan materi yang melebihi dari rancangan pembelajaran yang telah disusun dan ditetapkan. Hal ini menimbulkan kesulitan tersendiri karena faktanya perkembangan akses informasi makin terbuka luas dan cepat diperoleh. Jadi, guru perlu didukung dengan unsur lain dalam menjalankan pendidikan kesehatan reproduksi bagi remaja.

Jika dilihat dari sisi orang tua, persoalan kesehatan reproduksi ini sangat beragam penanganannya. Hal ini dipengaruhi oleh pekerjaan, pendidikan, dan tingkat ekonomi keluarga. Orang tua sudah mengajarkan tentang kesehatan reproduksi kepada anak-anaknya. Namun demikian, karena anak yang sudah masuk fase remaja memiliki keingintahuann yang tinggi dan cenderung ingin mencoba menjadikan anak secara sembunyi-sembunyi mengakses informasi dari internet tentang kesehatan reproduksi. Persoalan utama yang kemudian muncul adalah tidak semua informasi yang tersebar melalui internet berisi hal yang benar dan mengedukasi. Orang tua berharap ada komunikasi yang baik dan intens dengan semua pihak yang mampu membantu untuk mendidik dan mengawasi perilaku remaja terkait kesehatan reproduksi.

Dalam setiap kesempatan focus group discussion yang dilakukan, para volunteer terlibat secara aktif sehingga mereka dapat memahami kondisi yang sesungguhnya terjadi dan dapat melakukan pemetaan terkait kegiatan komunikasi konseling yang nantinya harus dilakukan. Pada tahap selanjutnya, dilaksanakan kegiatan pelatihan komunikasi agar para volunteer dapat memperoleh bekal yang memadai tentang cara dan teknik komunikasi yang tepat dalam menghadapi persoalan remaja khususnya terkait kesehatan reproduksinya. Pelatihan ini memberikan bahan kepada relawan untuk bisa menjalankan konseling secara efektif dan sesuai dengan kondisi yang dimiliki oleh remaja yang memiliki persoalan. Komunikasi yang baik akan menghasilkan output dan outcome yang optimal. Dalam kegiatan komunikasi kesehatan ini meyakinkan bahwa klien merasa aman dan nyaman dengan konselor sehingga dapat terbuka. Harapannya, dapat tergali akar persoalan yang dialami sehingga dapat ditemukan rekomendasi solusi yang tepat. Perubahan dapat difasilitasi melalui komunikasi yang dijalankan. Dengan demikian, diharapkan dampaknya pada kesejahteraan remaja. Hal ini merupakan salah satu ide dasar dari peran sosial yang dijelaskan oleh Andreasen (1995).

\section{Simpulan}

Pemahaman tentang situasi dan permasalahan yang dihadapi remaja oleh kader dan volunteer Pashmina membantu dalam menentukan isi/materi dalam konseling yang dijalankan. Selain itu, pengenalan terhadap problematika yang dialami remaja membantu relawan untuk memilih dan menjalankan teknik komunikasi yang tepat. Peningkatan kapasitas volunteer Pashmina membuat kepercayaan diri semakin bertambah dalam menjalankan konseling.

\section{Ucapan Terima Kasih}

Ucapan terima kasih kami sampaikan kepada: 
1. LP3M Universitas Muhammadiyah Yogyakarta yang telah memberikan pendanaan dalam kegiatah program pengbadian masyarakat di tahun 2019/2020;

2. Pimpinan Daerah Nasyiatul Aisyiyah Bantul yang telah menjadi mitra dalam program peningkatan kapasitas kader Pashmina melalui pelatihan teknik komunikasi konseling;

3. volunteer Pashmina yang telah berpartisipasi aktif dalam penyusunan, pelaksanaan proram; dan

4. siswa, orang tua, guru SMP Muhammadiyah 2 Bambanglingpuro yang telah memberikan informasi terkait kesehatan reproduksi di kalangan remaja.

\section{Daftar Pustaka}

Andreasen, Alan R. (1995). Marketing Social Change: Changing Behavior to Promote Health, Social Development, and the Environment. San Fransisco: Jose-Bass.

Badan Kependudukan dan Keluarga Berencana Nasional. (2018). Survei Demografi dan Kesehatan Indonesia 2017: Buku Remaja. Jakarta: Badan Pusat Statistik Kementerian Kesehatan.

Badan Kependudukan dan Keluarga Berencana Nasional. (2018). Survei Demografi dan Kesehatan Indonesia 2017. Jakarta: Badan Pusat Statistik Kementerian Kesehatan.

Maulina, N. \& Hanief, L. (2015). Kampanye Kesehatan ASI for Baby Kalsel untuk Meningkatkan Motivasi Pemberian ASI Eksklusif hal 23 - 42, dalam Ishak, Aswad (ed), Komunikasi dan Isu Publik, Yogyakarta : ASPIKOM - Universitas Katolik Widya Mandala Surabaya - Universitas Kristen Petra Surabaya - Universitas Muhammadiya Malang - Buku Litera.

Surahman, H.K., Netraningrum, E.M., Wulandari, F. Buku Panduan Pashmina. S. Irmawati, ed. Jakarta, Indonesia: Pimpinan Pusat Nasyiatul Aisyiyah. nasyiah.or.id. 